\title{
A prospective, observational audit of failed regional anaesthesia in 4085 caesarean sections at a tertiary care hospital
}

\author{
Seema Partani ${ }^{1}$, Yogendra Singhal ${ }^{2, *}$, Sunanda Gupta ${ }^{3}$ \\ ${ }^{\mathbf{1}}$ Associate Professor, ${ }^{3}$ Professor \& HOD, Dept. of Anaesthesia, Geetanjali Medical College and Hospital, Udaipur, Rajasthan, \\ ${ }^{2}$ Assistant Professor, Dept. of Anaesthesia, Rabindranath Tagore Medical College, Udaipur, Rajasthan, India
}

*Corresponding Author:

Email: singhalyogi@yahoo.co.in

Received: $16^{\text {th }}$ June, 2017

Accepted: $20^{\text {th }}$ June, 2017

\begin{abstract}
Introduction: A prospective observational study was conducted in 4085 caesarean sections performed under Regional anaesthesia (RA) from February 2014 to January 2017 in tertiary care centre. The incidence and various contributing factors leading to total or partial failure of RA and the conversion rate to GA were determined.

Materials and Methods: All parturients posted for elective or emergency caesarean section received 10-12 mg $0.5 \%$ of hyperbaric bupivacaine added to $25 \mu \mathrm{g}$ of inj. Fentanyl, administered through a $25-27 \mathrm{G}$ Whitacre needle. A structured proforma was prepared to note the demographic data, type of RA, insertion position, position after insertion, local anesthetic volume, loss of sensation to pin prick and grade of motor block.

Results: In this 3 year period 4085 CS were performed, out of which 4054 (99.27\%) were conducted under RA, [4034 (99.5\%) under spinal anesthesia, $14(0.34 \%)$ under CSE and $6(0.14 \%)$ under epidural]. $30(0.73 \%)$ cases received GA primarily, the incidence of conversion rate from neuroaxial anesthesia to GA was $100(2.5 \%)$ out of which $1.77 \%$ were of elective surgery and $3.1 \%$ were in emergency surgery. Partial failure occurred in $1.68 \%$ and complete failure in $0.79 \%$ patients. Spinal failure occurred due to anesthetic factors like early start of surgery, before establishment of adequate block, inadequate dose of LA, inappropriate recording of block, ineffective batch of drug and technical or surgical factors.

Conclusion: Minimizing the incidence of block failure requires close attention to minute details.
\end{abstract}

Keywords: Failed Spinal, Failed Intubation, Regional Anesthesia.

\section{Introduction}

Regional anaesthesia is preferred in obstetric cases, as it is safer than general anaesthesia. ${ }^{1}$ Spinal anaesthesia is one of the most reliable regional technique with minimum risk of failure, ${ }^{2}$ insertion of needle is relatively easy and straightforward and CSF provides a clear indication of successful placement. There is rapid onset of drugs action and excellent anaesthesia, ${ }^{3}$ along with the cheaper cost of spinal anaesthesia compared to epidural technique is another reason for its increasing use. However spinal anaesthesia is not without complications. One disadvantage of it is the possibility of failed spinal block. ${ }^{4}$ At times when despite easy insertion and drug administration there may be no block or inadequate block. Inadequacy may relate to extent quality or duration of local anesthetic agent. ${ }^{2}$ Failed spinal anaesthesia (FSA) is defined as partial or incomplete spinal block requiring supplemental analgesia or conversion to general anaesthesia. ${ }^{5}$ Objective outcome include conversion to general anaesthesia, conversion to any different form of anaesthesia or pain during surgery. ${ }^{6-8}$ According to Royal College of Anesthesiologist (RCA) ${ }^{9}$ for the obstetric anaesthetic practice acceptable conversion rate should be less than $1 \%$ for elective caesarean section (CS) and less than 3\% for emergency CS. Inadequate block can lead to grave intra operative complications, hence the anesthesiologist must be aware of all possible causes of failure so as to minimize the risk.

\section{Aims of Study}

Primary outcome measures included identification of incidence of failed RA block and Secondary outcome measures to identify the risk factors contributing to the failure.

\section{Materials and Methods}

This study was conducted in Dept. of Anaesthesia, Geetanjali Medical College and Hospital, Udaipur, after approval from institutional ethical committee. It was a three year observational study from February 2014 to January 2017. All the parturients undergoing caesarean section were included in the study.

Method of regional anaesthesia (RA) was in the form of spinal, epidural and combined spinal epidural technique. Partial failure was defined as when a single dose of analgesic drug or a small dose of I.V. induction agent used to supplement RA. When RA was converted to complete general anaesthesia with intubation or repeat spinal was given then it was termed as complete failure. Regional blocks were performed by anesthesiologist. After thorough preanesthetic evaluation and consent an 18 G I.V. cannula was inserted and I.V. fluid (Ringer Lactate) started. Standard monitoring included non-invasive blood 
pressure, pulse oximetry and ECG. RA block was given with full aseptic precautions preferably under left lateral position at L3-L4/ L4-L5 interspace as per decision of attending anaesthesiologist.

Subarachnoid block was given with $25 \mathrm{G} / 27 \mathrm{G}$ Whitacre needle. A free flowing clear CSF was confirmed and 10-12 mg of injection bupivacaine heavy $0.5 \%$ with $25 \mu \mathrm{g}$ inj. Fentanyl was injected into intrathecal space. Gauge of spinal needle and drug doses were changed according to the patient weight and height. Epidural block was performed using $18 \mathrm{G}$ Touhy needle. $15-20 \mathrm{ml}$ of $2 \%$ lidocaine was given in epidural space, either single shot or as an epidural extension in already placed catheter for labour analgesia. CSE was given by $27 \mathrm{G}$ Whitacre spinal needle inserted via $18 \mathrm{G}$ Touhy epidural needle and 1.5 $\mathrm{ml}(7.5 \mathrm{mg})$ bupivacaine heavy $0.5 \%$ with $25 \mu \mathrm{g}$ fentanyl was given in subarachnoid space followed by epidural extension with $5 \mathrm{ml}$ of normal saline.

After performing the block, the patient was placed in supine position and wedge under right buttock was placed. Level of sensory blockage was assessed by loss of sensation to pin prick. Bromage score was used to assess motor block. Surgery was allowed when there was loss of pin prick sensation upto the level of T5. If T5 level was not achieved even after 10 mins of spinal/ CSE or 15 mins of epidural block further steps were taken, depending on whether it was a partial or complete failure of block. When sensory level was below T10, it was complete failure and managed with general anaesthesia with intubation or repeat spinal depending upon the situation at that time. When sensory level was < T5 to T10 it was partial failure and supplemental analgesia was given.

A structured proforma was prepared to note the demographic data, type of RA, insertion position, position after insertion, local anesthetic volume, loss of sensation to pinprick and grade of motor block.
Caesarean section either emergency or elective with any associated medical illness were also recorded. Emergency and elective cases classified according to category 1 to 4 in which 1 and 2 were taken as Emergency and 3-4 were elective.

\section{Statistical Analysis}

Student ' $t$ ' test and chi square test was used to analyze the predisposing factors related to failure of block. $\quad \mathrm{P}<0.05$ was considered as statistically significant.

\section{Results and Observations}

We observed overall failure rate in spinal anesthesia cases which was $2.5 \%$ (100/4034 cases). No failure was observed in CSE and Epidural anesthesia which might be because of less number of cases. Partial failure was observed in $1.68 \%(68 / 4034)$ and complete failure in $0.79 \%$ (32/4034). 24/4034 $(0.59 \%)$ were converted into GA and repeat spinal was given to 8 $(0.11 \%)$ patients only.

Incidence of Caesarian Section and Failure of Regional Anaesthesia is shown in Flowchart 1 and Fig. 1.

In our study $97 \%$ of emergency caesarean section and $99 \%$ of elective caesarean section were carried out under RA. Failure of RA in Emergency cases was 3.1\% while it was $1.77 \%$ in Elective cases. (Table 1).

Sensory level of SAB was below T10 in 32/4034 $(0.79 \%)$ cases and all had complete failure. In all cases of partial failure sensory level of SAB was observed between T5 to T10 (Fig. 2).

Possible risk factors found in our audit were Urgency of surgery, ineffective drug action, inactive local anaesthetic solution, inappropriate recording of block, failure of correct positioning, lack of free flow of CSF, surgical causes and other (Table 2). 
Flowchart 1: Incidence of Caesarian Section and Failure of Regional Anaesthesia

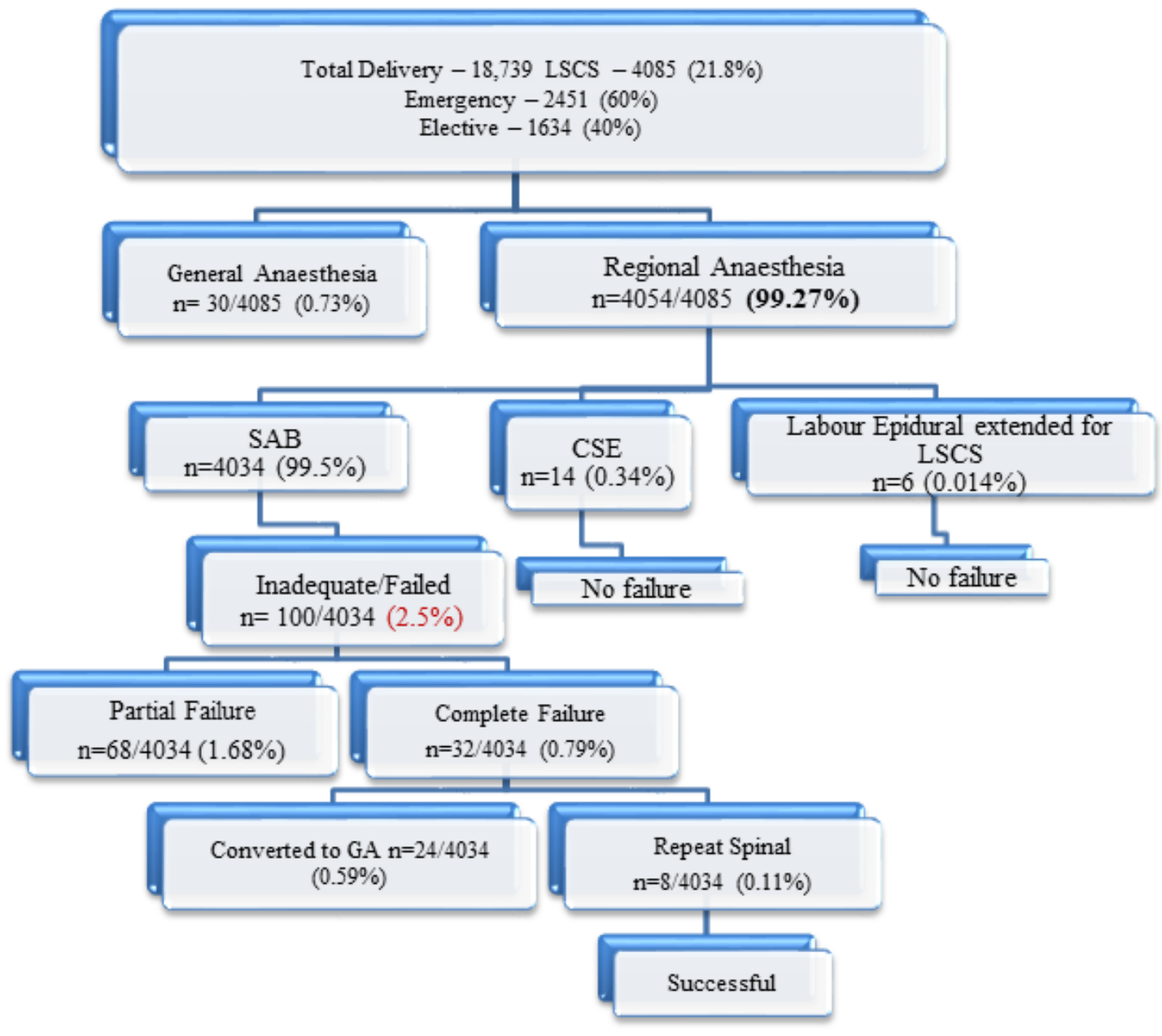

Table 1: Best Practice in Our Institute

\begin{tabular}{|l|c|c|}
\hline & $\begin{array}{c}\text { Emergency } \\
\text { (Cat I \& II) }\end{array}$ & $\begin{array}{c}\text { Elective } \\
\text { (Cat III \& IV) }\end{array}$ \\
\hline CS carried out with RA & $97 \%$ & $99 \%$ \\
\hline Failure of RA & $3.1 \%$ & $1.77 \%$ \\
\hline
\end{tabular}

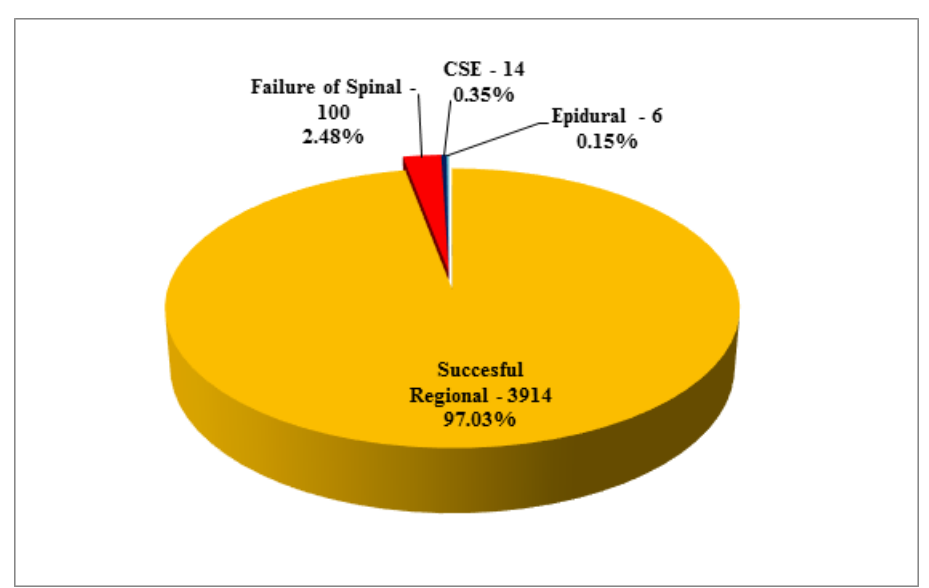

Fig. 1: Incidence of Failure of Regional Anaesthesia 


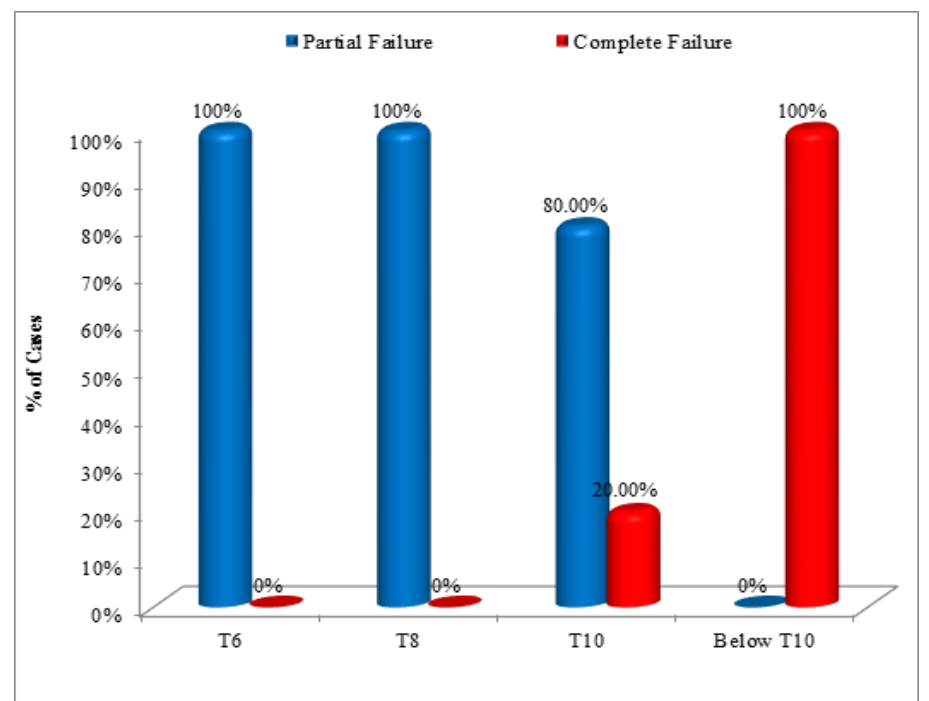

Fig. 2: Sensory Level in Failed Spinal Cases

Table 2:

*p $<0.05$ (Significant)

\begin{tabular}{|l|c|c|c|}
\hline \multicolumn{1}{|c|}{ Possible Risk Factors } & $\begin{array}{c}\text { Partial } \\
\text { Failure }\end{array}$ & $\begin{array}{c}\text { Complete } \\
\text { Failure }\end{array}$ & $\begin{array}{c}\text { Total } \\
(\mathbf{n = 1 0 0})\end{array}$ \\
\hline Urgency of Surgery* & $27(84.37 \%)$ & $5(15.62 \%)$ & $32(32 \%)$ \\
\hline Ineffective Drug Action* & $2(20.00 \%)$ & $8(80.00 \%)$ & $10(10 \%)$ \\
\hline Inactive Local Anaesthetic Solution & $3(37.50 \%)$ & $5(62.50 \%)$ & $8(8 \%)$ \\
\hline Inappropriate recording of block* & $20(90.90 \%)$ & $2(9.10 \%)$ & $22(22 \%)$ \\
\hline Failure of Correct Positioning & $10(66.66 \%)$ & $5(33.33 \%)$ & $15(15 \%)$ \\
\hline Lack of Free Flow of CSF & $4(44.44 \%)$ & $5(55.56 \%)$ & $9(9 \%)$ \\
\hline Surgical Causes & $1(50.00 \%)$ & $1(50.00 \%)$ & $2(2 \%)$ \\
\hline Others (cause not known) & $1(50 \%)$ & $1(50 \%)$ & $2(2 \%)$ \\
\hline Grand Total & 68 & 32 & 100 \\
\hline
\end{tabular}

\section{Discussion}

Regional anaesthesia is a boon for obstetric surgeries as there is a dramatic decrease in the incidence of maternal mortality with increasing use of neuraxial anaesthesia. Although spinal anaesthesia has many advantages but in case of failed spinal it is very distressing for patient and anesthesiologist. There are several reports of failed spinal in literature..$^{2-4}$ The incidence of which vary in different studies.

This prospective observational study investigated the incidence and characteristics of failed regional anaesthesia and its further management. The identification of potential risk factors for block could help the anesthetist to ensure a more successful block. During 3 year study period, 4085/18739 (21.8\%) caesarean deliveries were conducted [2451(60\%)emergency, 1634(40\%)-elective]. The proportion of caesarean section performed under regional anaesthesia has greatly increased in the last two decades. The percentage use of general anaesthesia for caesarean section has become a marker of quality of obstetric anaesthetic practice. ${ }^{10,11}$

In present audit out of 4085 caesarean section 4054 $(99.27 \%)$ were carried out under regional anaesthesia.
The Royal College of Anesthesiologist in United Kingdom has proposed that $>95 \%$ of elective caesarean section and $>85 \%$ of emergency CS should be under RA and conversion rate to general anaesthesia (GA) should be $<3 \%$ for emergency and $<1 \%$ for elective cases. In present audit, overall failure was 100/4054 $(2.46 \%)$, which is in accordance with Royal College of Anesthesiologist standards. ${ }^{9}$

Reide et al $(2008)^{12}$ found an average conversion rates from regional to general anesthesia as $38 \%$ for emergency and $0.8 \%$ for elective CS (Epidural > CSE > Spinal). They suggested a greater conversion rate with CSE than spinal for emergency cases but not for elective CS. In our study though no failure was observed in epidural $(n=6)$ and CSE $(n=12)$, but it cannot be concluded that epidural and CSE have lower failure rate because of such a small sample size. Rafi et al $(2010)^{13}$ showed similar results. Kinsella et al $(2008)^{14}$ observed incidence of failure $0.8 \%$ for elective CS and $4.9 \%$ for emergency CS. Range of failure of regional anesthesia was found variable in prospective and retrospective studies because of broader definition of failure. In our study, out of 100 failed cases, 68 patients of partial failure were managed with 
supplemental inj. Fentanyl I.V / inj. Ketamine alone or in combination with inj. Propofol according to severity of pain. Out of 32 cases of complete failure, inadequate anesthesia was diagnosed in 8 cases, in which repeat spinal with identical or lower dose of LA agents were given. A second dose may be too small, again resulting in an inadequate sensory level or too large leading to high level of anesthesia. ${ }^{15}$ However, no such complication was observed in present study.

In this study early start of surgery before establishment of adequate block was responsible for 32 cases of failure and this was a statistically significant reason for partial failure $(27 / 32,84.37 \%)$. In these partial failure cases sensory level was T10 to T8 and required single dose of analgesic supplemented as above. In remaining 5 cases of complete failure sensory level was achieved upto T10 even after 10 mins. Kinsella et al (2008) mentioned that inadequate preoperative block was associated with increased risk of intraoperative failure and in cases where the surgery had started in presence of inadequate block because of urgency, the failure rate was $20 \%$.

Fettes et al (2009) described that the possible mechanism of failure of spinal anesthesia could be considered in five phases in sequence: problem with lumbar puncture, solution injection, spreading of drug through CSF, drug action on spinal nerve root, cord and subsequent patient management.

In present study difficulty in lumbar puncture was attributed to difficulty in patient position in 15\% patients. Abnormalities of spine, obesity, patient's anxiety make correct positioning and needle insertion difficult.

The lack of free flow of CSF was attributed for failure in $9 \%$ cases. Increased incidence of failure had been recorded when injection of LA was made in the absence of free flow of CSF. ${ }^{16}$

Ineffective drug action was attributed to inadequate dose and baricity, ${ }^{17}$ which resulted in Ten percent cases of failure were because of this. In fact, the chemical stability of the amide drugs and modern standards of pharmaceutical manufacture mean that drug inactivity is most unlikely cause, but it remains a possibility which has to be eliminated. ${ }^{2}$

Inappropriate recording of block was observed statistically significant in present study. This is because of low literacy rate of rural population in our area. There were two cases of CS in which adhesions were more, which required more manipulation during surgery, which resulted in pain and discomfort to patient. One patient was relieved with I.V. supplement, but another patient required GA with intubation for complete relaxation. Singh et $\mathrm{al}^{18}$ (2009) found that postpartum sterilization was an independent factor associated with need for I.V. fentanyl and entonox supplementation while adhesions were described as reason for total failure.
In present study we couldn't find any reason for failure in 2 cases. Demographic data were not found to be significant in our study.

Purva et al (2012) ${ }^{19}$ described common reasons for failure which included staff inexperience, obstetric preference for GA, high number of maternal request for GA, especially in ethnic minority women, misclassifying urgency, poor selection of RA type in complex cases, and inappropriate recording of block.

Kinsella et al (2008) described that type of anesthesia, operative urgency, BMI, no previous caesarean and indication for cesarean section as acute fetal distress or maternal medical condition were related with preoperative failure, whereas inadequacy of preoperative anesthetic block and duration of surgery beyond $90 \mathrm{~min}$ were important risk factors for intraoperative failure.

\section{Conclusion}

Spinal anesthesia is safe, simple and reliable technique but failure can occur at any time by any anesthesiologist, no matter how experienced. Failure can be minimized by proper evaluation of patient anatomy related to procedure, proper storage of anesthetic agents, appropriate selection of dose alongwith correct positioning during puncture and immediately after the administration until it is fixed to the tissue.

We conclude that most common cause of failure of RA during CS are urgency of surgery, and inappropriate recording of block. Minimizing the incidence of failure is obviously a prerequisite for gaining the benefits of spinal anaesthesia. Identifying avoidable cause of inadequate block help to minimize incidence of failure.

\section{References}

1. Kinsella S.M., Girgirah K, Scrutton M.J.L. Rapid sequence spinal anesthesia for category-1 urgency caesarean section: a case series. Anaesthesia 2010, 65:664-9.

2. Fettes P.W.D., Janson J.R. and Wildsmith J.A.W. Failed spinal anesthesia mechanism management and prevention. Br J Anesth 2009;102:739-48.

3. Hoppe J. Popham P. Complete failure of spinal anaesthesia in obstetrics. Intern J of Obstet Anaesth 2007;16:250-5.

4. Lamacraft G. Complications associated with regional anaesthesia for Caesarean section. S Afr J Anaesth Analg. 2004;10:15-20. http-IJ dx.doi.org/10.1080/22201173.2004. 10872346

5. Szypula K, Ashpole K, Bogod D, Yentis SM, Mihai R, Scott $\mathrm{S}$ et al. Litigation related to regional anaesthesia: an analysis of claims against the NHS in England 19952007*. Anaesth. 2010;65:443-52. http://dx.doi.org/10.1)11/)*.1365-2044.2010.06248.

6. Jenkins JG, Khan MM. Anaesthesia for Caesarean section: a survey in a UK region from 1992 to 2002. Anaesthesia 2003;58:1114-8.

7. Bloom SL, Spong CY, Weiner SJ, landon MB, Rouse DJ, Varner MW et al. Complications of anesthesia for 
cesarean delivery. Obstetric \& Gynecology

2005;106:281-7.

8. Riley ET, Papasin J. Epidural catheter function during labor predicts anesthetic efficacy for subsequent cesarean delivery. International Journal of Obstetric Anesthesia 2002; 11: 81-4.

9. Kinsella M ea, Royal College of Anaesthetists / Raising the Standard: a compendium of audit recipes, $3^{\text {rd }}$ Edition, Year 2012.

10. Thomas J, Paranjothy S. Royal College of Obstetricians and Gynaecologists Clinical Effectiveness J/T Support Unit. The National Sentinel Caesarean Section Audit Report. London: Royal College of Obstetricians and Gynaecologists Press, 2001.

11. Colvin JR. Raising the Standard. A Compendium of Audit Recipes for Continuous Quality Improvement in Anaesthesia, 2nd edn. London: The Royal College of Anaesthetists, 2006.

12. Reide PJW, Durbridge J, Yentis SM. Conversion from regional to general anaesthesia for emergency and elective caesarean section. Int J Obstet Anesth 2008; 17:s32.

13. Rafi MA, Arfeen Z, Misra U. Conversion of regional to general anaesthesia at caesarean section : Increasing the use of regional anaesthesia through continuous prospective audit. Int J Obstet Anesth 2010;19 (2):17982.

14. Kinsella S.M. A prospective audit of regional anaesthesia failure in 5080 Caesarean sections. Anaesth 2008;63(8):822-32.

15. Steiner L.A., Hauenstein L. Ruppen W., Hampl K.F. and Seeberger M.D. Bupivacaine concentrations in lumbar cerebrospinal fluid in patients with failed spinal anaesthesia.Br. J. Anaesth 2009;102(6):839-44.

16. Levy JH, Islas JA, Ghia JN, Turnbull C. A retrospective study of incidence and causes of failed spinal anaesthetics in a university hospital. Anesth Analg 1985;64(7):705-10.

17. Munhall RJ, Sukhani R, Winnie AP. Incidence and etiology of failed spinal anaesthetics in a university hospital: a prospective study. Anesth Analg 1988;67(9):843-8.

18. Sng BL, Lim Y, Sia ATH. An observational prospective cohort study of incidence and characteristic of failed spinal anaesthesia for caesarean section. Int J Obstet Anesth 2009;18(3):237-41.

19. Purva M, Russell IF, Kinsella M. Caesarean section anaesthesia: technique and failure rate. In: Raising the standard. A compendium of audit recipes. Third Edn. London: Royal College of Anaesthetists, 2012:36-7. 